Association for Information Systems AIS Electronic Library (AISeL)

Wirtschaftsinformatik Proceedings 2005

Wirtschaftsinformatik

February 2005

\title{
Revenue Models for E-Learning at Universities
}

Jan Mendling

Vienna University of Economics and Business Administration (WU Wien)

Gustaf Neumann

Vienna University of Economics and Business Administration (WU Wien)

Andreas Pinterits

Vienna University of Economics and Business Administration (WU Wien)

Bernd Simon

Vienna University of Economics and Business Administration (WU Wien)

Follow this and additional works at: http://aisel.aisnet.org/wi2005

\section{Recommended Citation}

Mendling, Jan; Neumann, Gustaf; Pinterits, Andreas; and Simon, Bernd, "Revenue Models for E-Learning at Universities" (2005). Wirtschaftsinformatik Proceedings 2005. 43.

http://aisel.aisnet.org/wi2005/43

This material is brought to you by the Wirtschaftsinformatik at AIS Electronic Library (AISeL). It has been accepted for inclusion in Wirtschaftsinformatik Proceedings 2005 by an authorized administrator of AIS Electronic Library (AISeL). For more information, please contact elibrary@aisnet.org. 
In: Ferstl, Otto K, u.a. (Hg) 2005. Wirtschaftsinformatik 2005: eEconomy, eGovernment, eSociety; 7. Internationale Tagung Wirtschaftsinformatik 2005. Heidelberg: Physica-Verlag

ISBN: 3-7908-1574-8

(C) Physica-Verlag Heidelberg 2005 


\title{
Revenue Models for E-Learning at Universities
}

\author{
Jan Mendling, Gustaf Neumann, \\ Andreas Pinterits, Bernd Simon \\ Vienna University of Economics and Business Administration (WU Wien)
}

\begin{abstract}
This paper addresses the recent discussions on business models for e-learning. Throughout this paper, we contribute to this discussion by presenting first evidence for the sustainability of e-learning systems at universities. We discuss the cases of Learn@WU,EducaNext, and HCD-Online using a triangulation case study design and present both empirical cost structures and potential revenue models. The paper shows that there is a significant potential for revenue, but one revenue model is hardly enough to cover the cost. The size of the target audience as well as the (marketing) qualifications of the personnel have been identified as critical success factors for the sustainability of an e-learning system.
\end{abstract}

Keywords: E-Learning, Business Model, Revenue Models, Case Study

\section{Relevance of Revenue Models for E-Learning}

The introduction of information technology in learning processes - commonly referred to as e-learning - offers academic institutions new possibilities to organize their educational processes. Various universities have implemented e-learning systems, both to save cost for classrooms and teaching staff as well as to improve the quality of teaching as such. However, the overall qualitative and quantitative impact of e-learning initiatives is difficult to measure. E-learning investments can be regarded as strategic investments of academic institutions that aim to achieve competitive advantage, both in terms of cost structures as well as effectiveness. Seufert defines a spectrum of e-learning supported organizations ranging from "traditional alma mater" to "pure virtual university", in order to systematically describe the different e-learning strategies of academic institutions [Seuf01].

The notorious under-funding of some universities in Central Europe has triggered discussions about new revenue sources in order to cover expenses of e-learning projects [DoSi03]. However, contradicting claims can be found concerning the financial aspects of e-learning initiatives. Schneider, for example, states that revenues can hardly be expected from online learning because people would be unwilling to subscribe and no cost can be saved in academic environments [Schn02]. Seufert, on the one hand, talks about investment in technological infrastructure to 
be cost-efficient, while, on the other hand, she mentions that high investment for tutors and coaching of supported students is needed [Seuf01]. Hoppe and Breitner state that web-based e-learning creates positive network effects and that it has a huge potential for additional revenues at low provision cost [HoBr04]. However, they also expect the success to depend upon high-quality content [HoBr04], which seems to contradict with low provision cost. Conclusions about how e-learning can become financially successful can hardly be drawn from these statements. Up to now, no empirically grounded estimations of revenue potential for e-learning at universities are available [Dohm03]. Furthermore, there is a deficiency in marketing and sales as well as a technical orientation of the projects that Cleuvers describes as "l'art pour l'art" [Cleu03].

By analyzing the cases of Learn@WU, EducaNext, and HCD-Online we aim to address this deficiency. We use a multi-perspective triangulation methodology to extract hypotheses from the cases. In particular, each case includes an empirical grounded cost structure and presents one potential revenue stream based on current market parameters. Our calculations provide insights into the factors that influence sustainability of e-learning business models at universities and offer a basis for further economic research into e-learning at universities. The rest of the paper is structured as follows. In Section 2 we explicate the terms e-learning and business model including related taxonomies. The methodology applied in this research is documented in Section 3. Section 4 introduces the cases of Learn@WU, EducaNext, and HCD-Online. We define revenue models for each case and calculate both empirical expenditures and hypothetical revenues that are based on parameters of each system and current market parameters. Moreover, we deduct factors that influence sustainability of revenue models for e-learning systems at universities. Section 4 concludes the paper and gives an outlook on future research.

\section{E-Learning and Related Business Models}

\subsection{What is E-Learning?}

E-Learning refers to the combination of learning and information technology, which provides new learning opportunities with less restriction on time and space. Academic e-learning initiatives aim at designing, implementing and introducing an e-learning system in a higher education institution. An e-learning system can be defined as a social and information technological system that supports learning processes (cf. e.g. [HoBr04]). An e-learning application is at the centre of an elearning system. It supports one or more processes of the educational value chain [GuNS01]. The value chain consists of the following activities: learning planning and curricula design; content development and brokerage; learning delivery and 
learner coaching, as well as assessment, evaluation, and credentialing (cf. Figure 1). Each of these activities can be supported by e-learning applications.

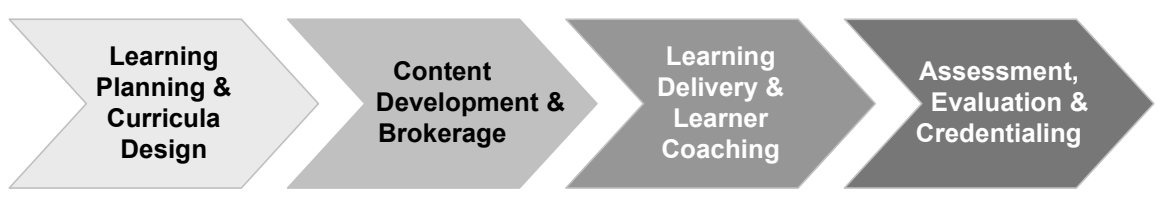

Figure 1: Educational Value Chain.

Applications for learning planning \& curricula design typically provide features for knowledge gap analysis and personnel development planning [KKGS04]. Applications for content development \& brokerage support the creation and acquisition of content. Authoring tools and online market places for courses or content are the type of application that can be found here. Applications for learning delivery \& learner coaching support (collaborative) learning in courses, which are delivered over distance or held in classrooms and lecture halls. These applications are often referred to as learning (content) management system and support communication between instructors and learners in asynchronous and synchronous mode. Applications for assessment, evaluation and credentialing are used to certify the learners' competency [Seuf01] or to evaluate the quality of the course. Course evaluation tools and test suites are the kind of applications supporting these processes.

In order to draw a complete picture of an e-learning system its different stakeholders have to been identified. An e-learning stakeholder in this context is an individual or an organization that is involved with the operations or may be affected by the existence of an e-learning application (analogous to [Free84]). In general, the e-learning stakeholders are a subgroup of the stakeholders of a university. The university can use e-learning to strengthen its relationship with stakeholders like e.g. alumni, faculty, or students. As all stakeholders have an interest in the sustainability of an e-learning initiative, a business model is the prerequisite for achieving this goal.

\subsection{Business and Revenue Models for E-Learning}

Since the collapse of the new economy hype, research into business models has attracted much attention in both academia and industry. Timmers defines a business model as an "architecture for products, services, and information flows, including a description of the various business actors and their roles; and a description of the potential benefits for the various business actors; and a description of the sources of revenues" [Timm00]. 
Early research has aimed to identify different categories of business models [cf. e.g. Timm98]. Wirtz and Kleineicken identify four categories of business models (content, commerce, context, connection) that are applicable for the Internet [WiK100]. Furthermore, they distinguish between direct and indirect as well as transaction-dependent and transaction-independent revenue generation. Recently, Rappa has introduced a taxonomy of 38 business models grouped into nine types: brokerage, advertising, information intermediary, merchant, manufacturer direct, affiliate, community, subscription, and utility [Rapp04].

Work inspired by conceptual modelling aims to identify the essential concepts of business models and the relationships between them. The e-business model ontology proposed by Osterwalder and Pigneur [OsPi02] extends earlier research and identifies four perspectives. The product perspective of a business model describes the products and services a company is offering and its value proposition. The customer relationship perspective defines who the target customers are, how the products are delivered to them, and how the relationship with them is build up and maintained. The infrastructure perspective specifies how infrastructure and logistics are organized efficiently. Finally, the financial perspective defines the revenue and the cost model of the business. In essence, the revenue model describes the sources of revenue of a business. Though a business model focuses on defining the business, it can also provide the basis for the definition of controlling measures like e.g. balanced scorecards [NoKa92].

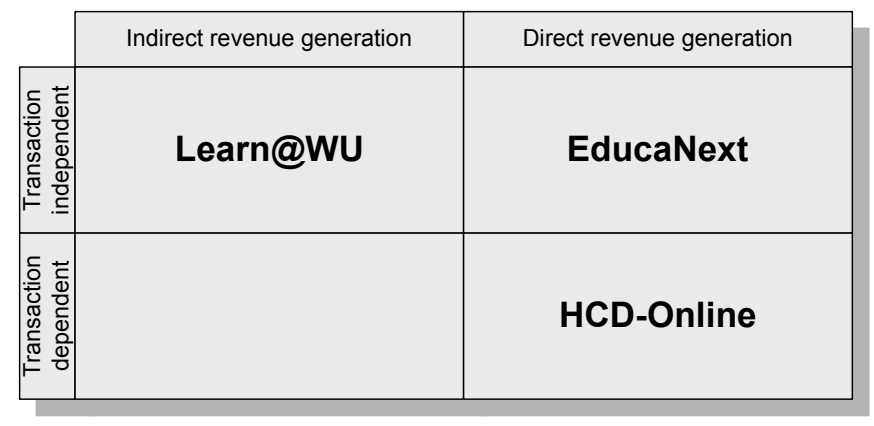

Figure 2: E-Learning Systems and Characteristics of Their Revenue Model.

In the area of e-learning appropriate business models have been discussed from the very beginning. Seufert presents different types of e-learning at universities and related business models [Seuf01]. The volumes edited by Bentlage et al. [Bent+02] and Dohmen and Michel [DoMi03] aim to take an inventory of academic e-learning and business models. In this context the question of sustainability is raised for e-learning business models [GuNS01, HoBr04]. The claimed potential for additional revenue is especially interesting for universities. In Section 4 we present three cases of e-learning systems at universities and focus on the financial dimension of business models. From these cases we aim to condense some 
insight into the revenue potential of e-learning systems. Figure 2 relates the three cases of Learn@WU, EducaNext, and HCD-Online to the revenue types identified in Wirtz and Kleineicken [WiK100].

\section{Methodology}

As there are no estimations of revenue potential for e-learning at universities available yet [Dohm03], we adopted an explorative case study approach [cf. Yin93]. Although this research design cannot provide empirically generalized predictions, we can nevertheless gain insight into the peculiarities of different revenue models for e-learning. Hence, the findings rely on analytical generalization and particulization [cf. Stak95 and Yin94].

We selected the three cases for the following reasons: The e-learning systems of the three cases address different activities of the educational value chain (cf. Figure 1). Learn@WU supports content development and learning delivery, EducaNext supports content brokerage, and HCD-Online supports learning planning. The cases also comprise different revenue models according to the classification schema of Wirtz and Kleineicken [WiK100]. For Learn@WU we discuss an advertising revenue model, for EducaNext a subscription revenue model, and for HCDOnline a brokerage fee revenue model. Furthermore, the systems of the cases address the needs of different e-learning stakeholders: Learn@WU targets students, EducaNext faculties, and HCD-Online the life-long learners. Finally, as our department is involved in the development of all three systems, we had direct access to financial and usage data. We were able to tap the different project members and to put together the empirical cost structure.

In order to draw a complete picture of the cases we used three types of evidence including documents, archival records, and interviews. Documents and archival records comprise project reports and calculations; web server log files; and statements of accounts. Furthermore, the calculations presented in this paper have been reviewed by key informants. Interviews were performed via phone and e-mail in June 2004. The interviewees had highly heterogeneous job titles such as assistant at a training service provider responsible for online market places, assistant to the managing director of an online market place, learning service manager of a university Alumni centre, sales personnel of a leading Austrian newspaper responsible for online-advertising, service manager of a faculty exchange portal, technical manager of a university e-learning project. In total, seven interviews were conducted.

By presenting three cases - Learn@WU, EducaNext, and HCD-Online - with different characteristics we comply with the research design of a multi-perspective data triangulation [cf. e.g. Stak95]. Furthermore, as different researchers have 
been involved in data gathering and interpretation, the study also suffices investigator triangulation criteria [Stak95].

\section{Three Cases of E-Learning Revenue Models}

\subsection{An Advertising Revenue Model for Learn@WU}

\subsubsection{Introduction to Learn@WU}

Learn@WU (https://learn.wu-wien.ac.at/) is an e-learning application developed at the Vienna University of Economics and Business Administration (WU for "Wirtschaftsuniversität"). It acts as a full service provider to first year students [Albe+03]. The Learn@WU project has been aligned to achieve the following goals of its stakeholders:

- Higher student satisfaction through better preparation for introductory exams, opportunities to getting in touch with peers online, and higher transparency of study goals.

- Increased learning performance through a collaborative learning approach and additional opportunities for interaction.

- Higher faculty satisfaction by easing the process of publishing course material on the web, efficient mass administration and delivery of courses, electronic homework assignments, and marking.

- Standardizing the knowledge level of students entering the second part of their studies by collaborative development of joint course materials among different departments.

- Creating a modern image of the university while reducing teaching cost through decreasing the need for classrooms and lecture halls while increasing throughput through half-semester courses, and off-term studies (Summer School).

In order to achieve these goals, Learn@WU has become an integral part of the curriculum and the teaching strategy of first year courses. As a consequence, Learn@WU is a heavily used system. At the time of writing, it holds 19,638 learning resources ranging from online text books over glossary terms to online exercises. More than 11,800 users have been registered, which makes Learn@WU assumed to be one of the most active learning environments in operation at universities worldwide [Albe+03]. At the same time Learn@WU is one of Austria's most 
heavily used websites with web traffic similar to the online portal of the Austrian newspaper Presse.at.

\subsubsection{The Cost Structure of Learn $@ W U$}

The total cost of the Learn@WU system can be subdivided into the following categories: technical server infrastructure, personnel, office infrastructure, and additional cost. We calculated the cost with actual empirical figures from the Learn@WU project documentation and interrogations. In this calculation we did not take into account any savings realized through implementation of the system (less classes hold, less assessment cost). Missing values were supplemented by reasonable estimations derived from secondary document research, e.g. for staff training cost we took $1.3 \%$ of total personnel cost which is equivalent to the average training investments of Austrian companies [Paul03]. A more detailed calculation is summarized in Table 1. All estimations are marked by an asterisk.

Personnel cost is the major cost block of the Learn@WU system. At the moment 28 staff members (full-position equivalents) are involved in the project. This includes content developers, system developers, support personnel for legal, pedagogical, and technical issues as well as administration staff. As the existing network infrastructure of the university can be used, no additional network costs arise. Learn@WU builds upon a learning content management system software package, called OpenLTS, which is based on an enhanced and customized version of the open-source software OpenACS [cf. Oacs04] and DotLRN [cf. Lrn04]. Consequently, cost for system development occur, but no licensing fee. Office infrastructure is made up of cost for workstations and office space.

Additional cost are split up in detail in Table 1. The implementation of the advertising revenue model requires additional technical infrastructure as well as resources dedicated to sales and administration. For both subjects a make or buy decision applies; i.e. first, implementation and maintenance of an ad-server (one staff member) versus hyperlinking to a third-party ad-server; and second, employment of a sales person versus charging a specialized agency with the sale of ads. Our considerations base on execution of all tasks by the university itself. Altogether the cost of Learn@WU would rise from $€ 1,279,620$ to $€ 1,418,600$ which means an increase by $€ 138,980$ or $11 \%$.

\subsubsection{Revenue Generation}

There are some indications that students - who often live on a tight budget - are not willing to pay extra for e-learning services [BeHu02]. In cases where users are unwilling to pay directly for content and services, advertising is frequently considered as a revenue model. This can also be applied to e-learning [cf. HoBr04]. However, the primary purpose of the e-learning system must not be negatively affected through advertisements; any disturbance of the basic learning process 
should be avoided. Therefore we consider only static ad banners in the standard size of $468 \times 60$ to be used. The basic parameter of our calculation is the number of page impressions (PI) delivered. It is a core measure for online customer contacts of websites. We geared this method to the recommendations of ÖWA (Österreichische Webanalyse), which complies with the German IVW (Informationsgesellschaft zur Feststellung der Verbreitung von Werbeträgern) standard. ÖWA is a voluntary association of Austrian online contractors and pursues the goal of collecting and publishing independent information about online advertising media [Öwa04].

COST OF LEARN@WU WITHOUT IMPLEMENTATION OF REVENUE MODEL

\begin{tabular}{|c|c|c|c|c|c|}
\hline Technical Infrastructure & & & & $€$ & 23,300 \\
\hline Personnel & & & & $€$ & $1,171,000$ \\
\hline Office Infrastructure & & & & $€$ & 52,920 \\
\hline & & & Detail & & \\
\hline Additional Cost & Amount & & Cost & $€$ & 32,400 \\
\hline Travel & 5 Trips & $€$ & 6,000 & & \\
\hline Staff training ${ }^{\star}$ ) & $28 \mathrm{Emp}$. & $€$ & 15,200 & & \\
\hline Consumables & $28 \mathrm{Emp}$. & $€$ & 8,400 & & \\
\hline Phone, Fax & $28 \mathrm{Emp}$. & $€$ & 2,800 & & \\
\hline Sum & & & & $€$ & $1,279,620$ \\
\hline
\end{tabular}

ADDITIONAL COST FOR IMPLEMENTATING THE REVENUE MODEL

Technical Infrastructure $€ \quad 1,300$

\begin{tabular}{|c|c|c|c|c|c|}
\hline Personnel*) & & & & $€$ & 109,700 \\
\hline Office Infrastructure & & & & $€$ & 3,780 \\
\hline Additional Cost & Amount & & Detail Cost & $€$ & 24,200 \\
\hline Travel $^{\star}$ ) & 10 Trips & $€$ & 10,000 & & \\
\hline Promotion*) & & $€$ & 10,000 & & \\
\hline Staff Training*) & $2 \mathrm{Emp}$. & $€$ & 1,400 & & \\
\hline Office Consumables & $2 \mathrm{Emp}$. & $€$ & 600 & & \\
\hline Phone, Fax & $2 \mathrm{Emp}$. & $€$ & 200 & & \\
\hline Accounting \& Legal Services*) & & $€$ & 2,000 & & \\
\hline Sum & & & & $€$ & 138,980 \\
\hline
\end{tabular}

Table 1: Cost Structure of Learn@WU.

Table 2 shows the number of PIs and the generated revenue from June 2003 to May 2004. In the first year of studies exams are held during examination weeks at 
the beginning, in the middle and at the end of every semester. This provokes recurring usage peaks in the last two weeks before the examination week. The calculated revenues build on the product of measured PIs multiplied by an estimated rate for one thousand PIs, the so-called thousand contact price (TCP). This estimation is based on actual market prices of leading Austrian contractors [cf. Öwa04]. As Learn@WU can offer very well-defined target groups, we decided to take an average price of $€ 30$ for thousand PIs, which is also in the middle of the current price range (the higher the precision of the chosen target group, the higher the price). Furthermore, we calculated with a utilization ratio of $30 \%$. An interview conducted with a field expert for online-advertising has shown that this figure can be regarded as a reasonable estimation. Additionally, this data is supported by other Austrian websites [cf. Trip04].

\begin{tabular}{rrr}
\multicolumn{1}{c}{ Month } & Page Impressions & Revenue \\
\hline Jun. 03 & $5,510,458$ & $€ 49,594$ \\
Jul. 03 & 382,352 & $€ 3,441$ \\
Aug. 03 & 504,585 & $€ 4,541$ \\
Sep. 03 & $4,314,393$ & $€ 38,830$ \\
Oct. 03 & $4,823,203$ & $€ 43,409$ \\
Nov.03 & $9,474,087$ & $€ 85,267$ \\
Dec. 03 & $3,032,123$ & $€ 27,289$ \\
Jan. 04 & $9,955,325$ & $€ 89,598$ \\
Feb. 04 & $8,011,179$ & $€ 72,101$ \\
Mar. 04 & $3,092,570$ & $€ 27,833$ \\
Apr.04 & $9,418,355$ & $€ 84,765$ \\
May 04 & $3,347,253$ & $€ 30,125$ \\
\hline Sum & $\mathbf{6 1 , 8 6 5 , 8 8 3}$ & $€ \mathbf{5 5 6 , 7 9 3}$ \\
\hline \hline
\end{tabular}

Table 2: Advertising Revenue Calculation for Learn@WU.

Table 2 illustrates that a significant revenue can be generated with online advertising. However, only a portion of the total cost could be covered (about $40 \%$ ). It seams to be sure that in this case - given the number of page impressions generated by Learn@WU - an investment in online advertising would certainly pay-off (especially given that the cost estimations were rather conservative). At the same time, the full cost model presented here needs to be questionned, since the university achieves further significant cost reduction (e.g. up to now more than 60,000 exams have been evaluated automatically) and higher customer satisfaction through the availability of the service. At times when the picture of a "modern" education provider also includes e-learning services, Learn@WU could also be seen as a paramount investment in order to continue to attract the best talents on the market. 


\subsection{A Subscription Revenue Model for EducaNext}

\subsubsection{Introduction to EducaNext}

EducaNext (http://www.educanext.org) is an academic exchange portal and knowledge community where members of higher education, research organisations, and professional communities can share, retrieve, and reuse learning resources [QuSi03]. It builds on an e-learning application called Universal Brokerage Platform (UBP). Until recently sharing knowledge over the Web had three major drawbacks: (1) faculty was not able to control the dissemination of its material, (2) faculty was not enabled to attach usage conditions to learning resource offerings, (3) faculty did not get rewarded for learning resources offerings.

EducaNext is a knowledge mediator that supports both the exchange of reusable educational materials based on open standards as well as collaboration of educators via the Internet. The portal is specifically designed to overcome the three obstacles mentioned above by (1) allowing users to define and manage closed exchange communities, (2) enabling providers to attach licenses to learning resource offerings, and (3) providing faculty a platform to gain international recognition.

In particular, EducaNext allows users to

- Participate in knowledge communities,

- Communicate with other experts in a field,

- Exchange learning resources, such as electronic textbooks, recorded lectures, presentations, lecture notes, case studies, quizzes, etc.,

- Deliver distributed educational activities, such as distributed courses, lectures, tutoring sessions, etc.,

- Distribute electronic content under license,

- Work together on the production of educational material.

The EducaNext service is free and open to any participant of the academic community. At the time of writing, 1,400 users from more than 250 institutions were registered at EducaNext. So far, they have provided about 500 learning resources, mostly in the disciplines computer science and information systems, business administration and management, as well as pedagogy and instructional design. EducaNext is managed by a Steering Committee (SC) which is in charge of the overall strategy of the portal, and by an Executive Board (EB) which runs daily operations such as application service provision, catalogue management, and dissemination. 


\subsubsection{The Cost Structure of EducaNext}

The cost structure of EducaNext is subdivided into technical server infrastructure, personnel, office infrastructure, and additional cost. Activities EducaNext has not been involved in such much lately. The figures were mainly taken from internal project documentation such as cost claims of EC-funded research projects. At its current state, personnel consume about $85 \%$ of the budget (see Table 3 ). The implementation of a subscription-based revenue model would require EducaNext to hire one additional employee. This person would be in charge of managing the registration and billing. She would also be in charge of organising SC meetings and preparing reports.

COST OF EDUCANEXT WITHOUT IMPLEMENTATION OF REVENUE MODEL

\begin{tabular}{|c|c|c|c|c|c|}
\hline Technical Infrastructure & & & & $€$ & 2,800 \\
\hline Personnel & & & & $€$ & 87,360 \\
\hline Office Infrastructure & & & & $€$ & 3,780 \\
\hline & & & Detail & & \\
\hline Additional Cost & Amount & & Cost & $€$ & 8,900 \\
\hline Travel & 7 Trips & $€$ & 7,000 & & \\
\hline Staff training ${ }^{*}$ ) & & $€$ & 1,100 & & \\
\hline Consumables & $2 \mathrm{Emp}$ & $€$ & 600 & & \\
\hline Phone, Fax & $2 \mathrm{Emp}$ & $€$ & 200 & & \\
\hline
\end{tabular}

ADDITIONAL COST FOR IMPLEMENTATING THE REVENUE MODEL

\begin{tabular}{|c|c|c|c|c|c|}
\hline Personnel*) & & & & $€$ & 36,400 \\
\hline \multicolumn{4}{|l|}{ Office Infrastructure } & $€$ & 1,890 \\
\hline \multirow[b]{2}{*}{ Additional Cost } & & & Detail & & \\
\hline & Amount & & Cost & $€$ & 47,900 \\
\hline Steering Committee Hosting*) & 2 & $€$ & 30,000 & & \\
\hline Travel & 5 Trips & $€$ & 5,000 & & \\
\hline Promotion & & $€$ & 10,000 & & \\
\hline Staff Training ${ }^{\star}$ ) & & $€$ & 500 & & \\
\hline Consumables & $1 \mathrm{Emp}$. & $€$ & 300 & & \\
\hline Phone, Fax & $1 \mathrm{Emp}$. & $€$ & 100 & & \\
\hline Accounting \& Legal Services*) & & $€$ & 2,000 & & \\
\hline Sum & & & & $€$ & 86,190 \\
\hline Total Cost including Revenue & entation & & & $€$ & 189,030 \\
\hline
\end{tabular}

Table 3: Cost Structure of EducaNext 
In contrast to the existing cost structure, over $50 \%$ of the cost increments arise from additional cost for travelling, promotion and hosting of the SC meetings. Facilitating personal meeting and collaboration of SC members is important for the success of the business model, since the coordination of marketing activities and $\mathrm{SC}$ activities is a critical success factor for attracting new clients. All these measures seem to be necessary to ensure a successful evolution of the system.

\subsubsection{Revenue Generation}

For EducaNext we chose to calculate a subscription-based revenue model. The design process has been inspired by the revenue models of similar initiatives such as Ariadne [Duva +01$]$ and Merlot [Hanl03]. The subscription-based revenue model seems appropriate because we cannot charge users directly. They already provide significant contributions through their engagement in the community. Furthermore, we have some empirical evidence that suggests that about $25 \%$ of EducaNext users would strongly dislike seeing ads appearing on the website [SiKö04].

Table 4 summarizes the proposed subscription types to be offered by EducaNext. Although the above-proposed subscription model has not been implemented yet, significant indications do exist that the model will be accepted by the market. For example, Merlot, a similar initiative, is charging its system partners $\$ 25,000$ a year and asks for $\$ 6,500$ in case of a campus partnership [Hanl03]. The Ariadne Foundation asks its institutional academic members for a yearly membership fee ranging from $€ 500$ (for small institutions or institutions with limited means) to $€ 4,500$. Corporate memberships are also supported, but they cost significantly more, ranging from $€ 2,500$ to $€ 15,000$ depending on the size of the enterprise (http://www.ariadne-eu.org/en/about/general/fees/fees.html). At the time of writing, the Ariadne Foundation had 39 registered institutional members in Europe. Ariadne offers individual memberships and restricts content access to its members. Merlot has no access limitation on the provided content; however one needs to register to comment on a learning resource.

We have investigated a set of variations of potential revenue streams, which would be necessary to cover the cost of the portal. The results indicate that a significant number of subscriptions need to be sold (between 50 and 55 assuming that a majority of about 35 will subscribe using the institutional subscription option). Currently users from more than 250 institutions are registered at EducaNext. However, selling up to 55 subscriptions ( $20 \%$ of all institutions) is a very demanding job, especially given the current state of the service. A recent user survey found out that EducaNext would need to be enriched with more learning resources and more community interaction to fully satisfy the needs of its clients. As a consequence, EducaNext would need to reduce cost or find alternative revenue streams in order to sustain its service, for example advertising and cross-selling of software and service provision. 


\begin{tabular}{|c|c|c|}
\hline Model & Rights & Yearly Fee \\
\hline $\begin{array}{l}\text { EducaNext } \\
\text { Full System } \\
\text { Subscription }\end{array}$ & $\begin{array}{l}+ \text { Own Universal Brokerage Platform (UBP) instance, } \\
\text { which can be fully customized (own hardware is pro- } \\
\text { vided). Changes to graphical design, taxonomies, } \\
\text { learning resource licenses, exchange and quality } \\
\text { management process, etc. can be applied. } \\
+\quad \text { Full availability of the UBP source code (all modules } \\
\text { designed and developed under Universal project) - } \\
\text { also for commercial projects (some or all UBP mod- } \\
\text { ules might become available as open source soft- } \\
\text { ware) } \\
+\quad \text { Software update subscription for all UBP modules } \\
\text { (without automatic installation) } \\
+\quad \text { Developer partnership (full support). }\end{array}$ & $€ 7,000$ \\
\hline $\begin{array}{l}\text { EducaNext } \\
\text { Community } \\
\text { Subscription }\end{array}$ & $\begin{array}{l}+\quad \text { Creation of own EducaNext community with own sub- } \\
\text { ject taxonomy } \\
+\quad \text { Management tool for user registration }\end{array}$ & $€ 5,000$ \\
\hline $\begin{array}{l}\text { EducaNext } \\
\text { Institutional } \\
\text { Subscription }\end{array}$ & $\begin{array}{l}+\quad \text { Primary support (reaction within } 1 \text { working day) for all } \\
\text { members of the university } \\
+\quad \text { Train-the-trainer material } \\
+\quad \text { All user interface language versions provided (transla- } \\
\text { tion as in-kind contribution needed) }\end{array}$ & $€ 3,000$ \\
\hline $\begin{array}{l}\text { EducaNext } \\
\text { Registered } \\
\text { User }\end{array}$ & $\begin{array}{l}+\quad \text { Provision of learning resources and feedback } \\
+\quad \text { Access also to all learning resources provided for } \\
\text { EducaNext users only }\end{array}$ & $€ 0$ \\
\hline $\begin{array}{l}\text { Unregistered } \\
\text { User }\end{array}$ & + Access to public learning resources & $€ 0$ \\
\hline
\end{tabular}

Table 4: EducaNext - Proposed Subscription Types

\subsection{A Brokerage Fee Model for HCD-Online}

\subsubsection{Introduction to HCD-Online}

The HCD-Online portal (http://www.hcd-online.com/) has been driven by the increasing demand for lifelong learning. High-skilled workers who are able to generate and acquire new knowledge and transfer this knowledge into their work environment constitute a key success factor for businesses. To remain competitive learning at the work place is increasingly in the focus of employees and employers. Many universities have reacted to this trend by offering continuing education in various granularities, ranging from half-day courses over lecture series to complete degree programmes. 
HCD-Online supports decision makers in selecting the "appropriate" learning resource from a heterogeneous and growing set of educational offers. It aims to provide an innovative online service which will enable lifelong learners and their stakeholders to perform learning planning processes more efficiently and effectively. In particular, the portal is designed to meet the following objectives [Gunn+04]:

- Give lifelong learners the opportunity to choose from a unique source of heterogeneous learning resource providers ranging from electronic bookstores to continuing education centres.

- Initiate a communication process that increases the quality of course selection decisions and learning transfer.

- Reduce the administration cost of selling, choosing, consuming, and evaluating courses.

- Create an efficient distribution channel for learning resource providers.

A database of training measures constitutes the core of the service. These measures are supplied by a number of learning resource providers that are interested in selling their goods and services via an electronic market place. Learning resource providers can also connect to the portal by taking advantage of the Web Service interfaces. The Simple Query Interface [SiDM04], for example, enables HCDOnline users to query databases beyond HCD-Online's database for educational offers.

At the portal, learning resource providers, lifelong learners and their stakeholders (e.g. mentors, human resource developers) are involved in processes such as learning goal analysis, search for learning resources, collaborative decision making, learning resource evaluation, and transfer analysis.

\subsubsection{The Cost Structure of HCD-Online}

The cost structure of HCD-Online is also subdivided into technical infrastructure, personnel, office infrastructure and additional cost (see Table 5). The project without implementation of the revenue model involves three employees with corresponding cost for office environment, workstations and travel cost. A small server is needed to host the system. Thus personnel cost consume the biggest part, about $90 \%$, of the budget.

Further budget is needed to carry out system integration projects [cf. Simo+04]. We estimated that three interoperability projects will be carried out in addition to the research funded integration of a commercial learning management system, an online book store, an electronic learning environment for IT, and a continuing education database. One project is aiming at the integration of the Learn@WU e-learning system; additional ones are planned for other databases of continuing education providers. Each of these three projects is calculated with $€ 10,000$. 


\subsubsection{Revenue Generation}

HCD-Online is a new portal, whose release is scheduled around the prospective publication date of this paper. In order to lower the barriers of entry for its prospective users and to achieve critical mass, we propose a revenue model that only charges a fee when a user actually benefits from the portal. For a learning resource provider this is the case when a course is sold to a company. For a learner, user value is created when a knowledge acquisition process is initiated, executed and evaluated. As a consequence of this design assumption, both, learning resource providers and learners will be charged a commission of $10 \%$ whenever a learning resource is contracted and consumed, but no other charges apply.

COST OF HCD-ONLINE WITHOUT IMPLEMENTATION OF REVENUE MODEL

\begin{tabular}{|c|c|c|c|c|c|}
\hline Technical Infrastructure & & & & $€$ & 2,800 \\
\hline Personnel & & & & $€$ & 149,240 \\
\hline Office Infrastructure & & & & $€$ & 5,670 \\
\hline & & & etailed & & \\
\hline Additional Cost & Amount & & Cost & $€$ & 8,000 \\
\hline Travel & 7 Trips & $€$ & 4,900 & & \\
\hline Staff training ${ }^{*}$ ) & & $€$ & 1,900 & & \\
\hline Consumables & 3 Emp. & $€$ & 900 & & \\
\hline Phone, Fax & $3 \mathrm{Emp}$. & $€$ & 300 & & \\
\hline Sum & & & & $€$ & 165,710 \\
\hline
\end{tabular}

ADDITIONAL COST FOR IMPLEMENTING THE REVENUE MODEL

\begin{tabular}{|c|c|c|c|c|c|}
\hline Technical Infrastructure & & & & $€$ & 0 \\
\hline Personnel & & & & $€$ & 36,400 \\
\hline Office Infrastructure & & & & $€$ & 1,890 \\
\hline Additional Cost & Amount & & $\begin{array}{r}\text { Detailed } \\
\text { Cost }\end{array}$ & $€$ & 34,900 \\
\hline Promotion & & $€$ & 2,000 & & \\
\hline Staff training*) & & $€$ & 500 & & \\
\hline Consumables & $1 \mathrm{Emp}$. & $€$ & 300 & & \\
\hline Phone, Fax & $1 \mathrm{Emp}$. & $€$ & 100 & & \\
\hline Accounting \& Legal Services*) & & $€$ & 2,000 & & \\
\hline Interoperability Projects & 2 Projects & $€$ & 30,000 & & \\
\hline Sum & & & & $€$ & 73,190 \\
\hline Total Cost including Revenue & on & & & $€$ & 238,900 \\
\hline
\end{tabular}

Table 5: Cost Structure of HCD-Online 
The average direct cost of a course amounts to $€ 732$ according to a study performed in Austria in 1999 [Paul03]. It is assumed that the portal will list about 2,000 courses from about 25 providers in the first year (These estimations can be considered conservative given that established seminar market places, such as Seminarmarkt.de and Seminar-Shop.com, list more than 10,000 courses from about 1,000 providers). We expect that about 1,000 users will be registered at the portal and take courses. This can also be considered as a rather conservative estimation given that, for example, 3,044 alumni of the Vienna University of Economics and Business Administration registered in the alumni club have consumed about 1,800 courses in 2003 (data according to an interview). This will lead to about 1,000 transactions a year, yielding to a revenue stream of $€ 146,400$.

\subsection{Consolidated Findings}

We have presented the three cases of Learn@WU, EducaNext, and HCD-Online to generate hypotheses concerning the impact of revenue models for e-learning. The findings that can be drawn from all three cases can be subsumed as follows:

- Revenue Potential Exists: We were able to show that in all three cases a significant revenue potential exists. This revenue potential can be seized to cover at least some parts of the cost of the e-learning portals. As a consequence, stakeholders in e-learning systems are advised to investigate these revenue models for their projects. This finding confirms a similar statement in Hoppe and Breitner [HoBr04].

- The Size of the Target Audience Matters: From the perspective of the presented cases the success of revenue models highly depends on its user base. In the Learn@WU case, for example, an online advertising model would be able to absorb at least one third of the whole cost. Considering the fact that the elearning system is able to ease the resource situation at a mass university like WU, revenue generation in this scale must be regarded as very attractive. On the other hand, the significantly smaller portals EducaNext and HCD-Online would require high utilization first, if they had to rely on the proposed revenue models. This finding is also supported by sustainability problems e-learning projects frequently encounter when they are solely based on an individual faculty member's initiative.

- Qualifications of the Work-Force Constitute a Critical Success Factor: Personnel turns out to be the dominant cost factor in all three cases. In all three cases about $90 \%$ of the cost are personnel cost. The implementation of our suggested revenue models implies even further employment of the work-force. Beyond the pure cost perspective, we consider skilled personnel to be a major success factor for the implementation of revenue models of e-learning systems. This argument stems from two points: all of our revenue models build on the utilization of the offered services. This makes success heavily dependent on 
marketing skills of the workforce. The second point is related to the quality of content which a successful e-learning system must provide. In the case of an electronic learning environment like Learn@WU this involves high personnel cost for skilled content developers and the implementation of a cost-effective development process. This confirms Seufert and her statement that high investments for personnel are needed [Seuf01], and it contradicts Hoppe and Breitner who talk about low provision cost [HoBr04].

- One Revenue Stream Alone Is Not Always Sufficient: In all three cases one revenue model alone is not able to cover the whole cost under an absorbed cost basis assumption. At the same time, all three cases have the potential for two or more revenue streams. In the case of Learn@WU, selling of content is currently investigated while EducaNext's underlying technology has served as a basis for consulting projects. If an e-learning system needs to be completely self-sustainable from a financial point of view, a revenue model building on different revenue streams seems to be appropriate. This conclusion is also supported by preliminary observations of successful national and international information delivery services. However, more empirical evidence needs to be provided.

- Cost-Savings Must Be Viewed from Multiple Perspectives: Concerning Schneider's statement that no cost can be saved [Schn02] we cannot provide evidence with these cases. In order to test his hypothesis, one would have to calculate cost savings of aligning the strategy of a university with an e-learning system. Reduced travel expenses, reduced teaching staff, and reduced classroom usage are only some sources of such potential savings. Yet, an overall cost-benefit analysis of a university's e-learning system is a challenging task, because it would have to include non-quantitative benefits like, for example, increased reputation. Accordingly, an e-learning system should not be regarded as a potential cash cow, but rather as an instrument to achieve specific goals of a university's strategy.

\section{Conclusion and Future Work}

In this paper we presented three case studies of e-learning systems with their empirical cost structure and potential revenue models. Our work gives some evidence to derive the following hypotheses. First, the implementation of a revenue model for an e-learning system has the potential to raise substantial income for the university. Nevertheless, the size in terms of traffic and user base needs to be significantly large in order to cover all cost. Furthermore, the role of personnel is crucial in different ways. On the one hand personnel accounts for most of the cost, on the other hand it has a major impact on the quality of the e-learning content and also in the attraction of new clients. 
Based on our exploratory study we will generate further hypotheses which we plan to test in future empirical studies together with representatives of the cost assumptions made. Additionally, the interdependences, compatibilities, and incompatibilities among various business models need to be further investigated. An empirically based break-even analysis could provide patterns that allow implementers to better judge whether a certain business model is also feasible for a specific e-learning system. In this context, questions such as how much traffic certain content must generate in order to pay-off at a given cost structure, how many courses must be sold to break-even with a course brokerage model.

\section{Acknowledgements}

This research is partly sponsored by the ELENA Project (http://www.elenaproject.org) under the grant IST-2001-37264. We would like to thank Alina Wolff for collecting empirical data. Under the lead of Prof. Juan Quemada (Universidad Politécnica de Madrid) EducaNext was initiated, he currently also chairs the EducaNext Steering Committee.

\section{References}

[Albe+03] Alberer, G., Alberer, P., Enzi, T., Ernst, G., Mayrhofer, K., Neumann, G., Rieder, R., und Simon, B.: The Learn@WU Learning Environment. In: Wirtschaftsinformatik 2003 -Band I, 2003: pp. 593-612.

[Bent+02] Bentlage, U., Glotz, P., Hamm, I. (eds.): E-Learning - Märkte, Geschäftsmodelle, Perspektiven. Verlag Bertelsmann-Stiftung, 2002.

[BeHu02] Bentlage, U., Hummel, J.: Märkte in den USA und in Deutschland im Vergleich. In: Bentlage, U., Glotz, P., Hamm, I. (eds.): E-Learning - Märkte, Geschäftsmodelle, Perspektiven. Verlag Bertelsmann-Stiftung, 2002: pp. 121-153.

[Cleu03] Cleuvers, B. A.: Bestandsanalyse der eLearning-Angebote der Hochschulen. In: Dohmen, D. and Michel, L. P. (eds.): Marktpotenziale und Geschäftsmodelle für eLearning-Angebote deutscher Hochschulen. Bertelsmann Verlag, 2003: pp. 29-92.

[Dohm03] Dohmen, D.: Ergebnisse. In: Dohmen, D. and Michel, L. P. (eds.): Marktpotenziale und Geschäftsmodelle für eLearning-Angebote deutscher Hochschulen. Bertelsmann Verlag, 2003: pp. 145-206.

[DoMi03] Dohmen, D. and Michel, L. P. (eds.): Marktpotenziale und Geschäftsmodelle für eLearning-Angebote deutscher Hochschulen. Bertelsmann Verlag, 2003.

[DoSi03] Dohmen, D. und Simons, S.: Geschäftsmodelle. In: Dohmen, D. and Michel, L. P. (eds.), Marktpotenziale und Geschäftsmodelle für eLearning-Angebote deutscher Hochschulen. Bertelsmann Verlag, 2003: pp. 145-206.

[Duva+01] Duval, E.; Forte, E.; Cardinaels, K.; Verhoeven, B.; Van Durm, R.; Hendrikx, K.; Wentland Forte, M. ; Ebel, N.; Macowicz, M.; Warkentyne, K.; Haenni, F.: The A- 
riadne Knowledge Pool System. In: Communications of the ACM. 44 (2001) 5, pp. $72-$ 78.

[Free84] Freeman, R. E: Strategic Management: A Stakeholder Approach. Boston, 1984.

[GuNS01] Guth, S.; Neumann, G.; Simon, B.: UNIVERSAL - Design Spaces for Learning Media. In: Sprague, Ralph H. (Hrsg.): Proceedings of the 34th Hawaii International Conference on System Sciences. Maui, USA 2001: IEEE.

[Gunn+04] Gunnarsdottir, S.; Kieslinger, B.; Küchler, T.; Simon, B.: From e-Learning to Learning Management: Results of an International Survey. In: Proceedings of 4th International Conference on Knowledge Management. Graz, Austria, 2004.

[Han103] Hanley, G. L.: MERLOT: Multimedia Educational Resource for Learning and Online Teaching. In: Proceedings of Ed-Media 2003. Honolulu, USA 2003: AACE, pp. 1281-1284.

[HoBr04] Hoppe, G. und Breitner, M. H.: Business Models for E-Learning. In: Rombach, D., Eicker, S., Pohl, K., Adelsberger, H., Wulf, V., Krcmar, H., und Pawlowski, J. (eds.): Multikonferenz Wirtschaftsinformatik (MKWI) 2004 - Band 1, 2004. pp. 3-18.

[Lrn04] dotLRN - An open source product to support learning and research communities. Accessed on 30 June 2004; http://dotlrn.org/.

[MeSi00] Meier, P.; Simon, B.: Reengineering Undergraduate Teaching by Introducing Internet-based Learning Information Systems. In: Hansen, H. R.; Bichler, M.; Mahrer, H. (Hrsg.): Proceedings of the 8th European Conference on Information Systems. Vienna, 2000.

[NoKa92] Norton D. and Kaplan, R.: The balanced scorecard: measures that drive performance, Harvard Business Review, 70 (1), 1992.

[Pau103] Pauli, W.: Betriebliche Weiterbildung. Statistik Austria. Wien, 2003.

[Rapp04] Rappa, M.: The Utility Business Model and the Future of Computing Services. In: IBM Systems Journal, Vol. 43, No. 1, 2004, pp. 32-42.

[Oacs04] OpenACS - The Toolkit for Online Communities. Accessed on 30 June 2004; http://openacs.org/.

[Öwa04] Österreichische Web Analyse (ed.): Wir über uns, 2004. Accessed on 24 June 2004; http://www.oewa.at/cgi-bin/frameset.pl?1

[OsPi02] Osterwalder, A. and Pigneur, Y.: An e-Business Model Ontology for Modeling eBusiness. 15th Electronic Commerce Conference e-Reality: Constructing the eEconomy, Bled, Slovenia, June 17-19, 2002.

[QuSi03] Quemada, J.; Simon, B.: A Use-Case Based Model for Learning Resources in Educational Mediators. In: Educational Technology \& Society (ISSN 1436-4522). 6 (2003) 4, pp. 149-163.

[Schn02] Schneider, W.: Bildung aus dem Netz - Chancen und Probleme. In: Fortmüller, R. (ed.): Komplexe Methoden, neue Medien in der Didaktik der Ökonomie. Manz Verlag Schulbuch, Wien, 2002: pp. 217-233. 
[SiKö04] Simon, B.; König, C.: EducaNext Service Evaluation. Vienna, Austria 2004: Accessed on 24 June 2004; http://www.educanext.org/educanext-eb-service-evaluation2004-06-22.pdf.

[Simo+04] Simon, B.; Dolog, P.; Miklós, Z.; Olmedilla, D.; Sintek, M.: Conceptualizing Smart Spaces for Learning. In: Journal of Interactive Media in Education. 2004 (1).

[SiDM04] Simon, B., E. Duval, and D. Massart. 2004. Simple Query Interface Specification: Accessed on 24 June 2004; http://nm.wu-wien.ac.at/e-learning/inter/sqi/sqi.pdf.

[Seuf01] Seufert, S.: E-Learning Business Models, Strategies, Success Factors and Best Practice Examples. In: R. De Fillippi, R. W. (ed.): Rethinking Management Education. Information Age Press, Greenwich, 2001.

[SiKö04] Simon, B.; König, C.: EducaNext Service Evaluation. Vienna, Austria 2004: http://www.educanext.org/educanext-eb-service-evaluation-2004-06-22.pdf.

[Stak95] Stake, R. E.: The art of case study research. $2^{\text {nd }}$ Edition. Thousand Oaks, USA. Sage Publications, 1995

[Timm00] Timmers, P.: Electronic Markets: Strategies and Models for Business-toBusiness Trading. Wiley, 2000.

[Timm98] Timmers, P.: Business Models for Electronic Markets. In: Journal of Electronic Markets, 8(2): pp. 3-8, 1998.

[Trip04] Tripple.net (ed.): Ad-locator Statistikdatenbank 05/2004. Accessed on 24 June 2004; http://www.tripple.net/ad-locator/stats.asp

[WiK100] Wirtz, B. und Kleineicken, A.: Geschäftsmodelltypologien im Internet. WiSt. 11:628-634. 2000.

[Yin93] Yin, R. K.: Case Study Research: Design and Methods. Thousand Oaks, USA. Sage Publications, 1993. 